\title{
EXPOSURE TO ORGANIC SOLVENT MIXTURE AND HEARING LOSS: LITERATURE OVERVIEW
}

\author{
MARIOLA ŚLIWINSKA-KOWALSKA \\ Department of Audiology and Phoniatrics, \\ Nofer Institute of Occupational Medicine \\ Łódź, Poland
}

\begin{abstract}
The chemical sector is the third largest industry in Europe. There is increasing evidence from epidemiological and clinical studies that occupational exposures to organic solvents may have detrimental effect on hearing. Most of the literature data concern one of the three following types of exposure to industrial solvents: mixed solvent exposure (the most common type); styrene-only exposure; and toluene-only exposure. This paper overviews the effects of industrial exposure to a mixture of organic solvents on hearing, with special regard to the dose-response relationship. Although the existing data make it difficult to derive a correlation between solvent concentration and hearing outcome, the current occupational exposure limits for solvents seem to be inadequate with respect to the effect that solvents may have on the auditory system.
\end{abstract}

Key words:

Paint and lacquer industry, Oil refinery, Jet fuel exposure, Dockyards, Risk of hearing loss

\section{INTRODUCTION}

Over the last few decades, several animal and human studies have reported on the effects of organic solvent exposure on the auditory system and its interaction with noise. This issue is extremely important in Europe, because the chemical sector is the third largest industry; about 1.7 million people are employed directly in the sector, and another 3 million perform jobs associated with the chemical industry.

The studies on rats have made it possible to conclude that several organic solvents, particularly styrene and toluene, can damage the cochlea. The ototoxicity of organic solvents in occupationally exposed workers is more difficult to prove. This is because the workplace concentration of chemicals is much lower than that used in animal studies, and the workers are usually exposed to a mixture of solvents with widely varying compositions and concentrations, which hinders the assessment of the effect of a single substance. Furthermore, in industrial settings, exposure to chemicals often coexists with an elevated level of noise, which makes it difficult to distinguish the solvent effect from the noise-induced hearing loss.

Most of the literature data assessing the auditory function in industrial workers concern one of the three categories of solvent exposure: (1) mixed solvent exposure (the most common type); (2) styrene-only exposure; and (3) tolueneonly exposure. This paper overviews the effects of industrial exposure to a mixture of organic solvents on hearing, with special regard to the dose-response relationship. It does not cover styrene-only exposure, toluene-only exposure or n-hexane-only exposure.

Received: April 2, 2007. Accepted: September 3, 2007

This paper was presented at the Workshop "Health effects of exposure to noise and chemicals - Ototoxicity of organic solvents" that was organized in Łódź on 15-16 November 2006, under the 6th European Framework Programme, the Marie Curie Host Fellowship for the Transfer of Knowledge "NoiseHear" Project (Contract No. MTKD-CT-2004-003137 — "Noise pollution effects on auditory organ — pathogenesis, risk assessment, prevention and treatment").

Address reprint requests to M. Śliwińska-Kowalska, PhD, Departament of Audiology and Phoniatrics, Nofer Institute of Occupational Medicine, św. Teresy 8, 91-348 Łódź, Poland (e-mail: marsliw@imp.lodz.pl). 


\section{NUMBER AND TYPE OF STUDIES}

Since 1984, sixteen original papers have investigated the relationship between occupational exposure to organic solvent mixture and hearing loss. The mixtures included xylene, toluene, methyl ethyl ketone (MEK), methyl isobutyl ketone, and others (ethanol, ethyl acetate, butyl acetate, ethyl benzene, thinner, cyclohexane, benzene). All the studies, except one, were cross-sectional epidemiological studies (10 papers) or clinical studies (5 papers) from occupational health clinics; one was a longitudinal 20-year follow-up study of workers exposed to noise (47 out of 319 workers co-exposed to noise and chemicals).

\section{POPULATION}

A total of almost 2400 workers exposed either solely to a mixture of organic solvents, or in combination with noise, were examined. Of this population, approximately 700 were exposed to organic solvent mixture (noise below $85 \mathrm{~dB}-\mathrm{A})$. The largest exposed groups were painters, and workers in paint and lacquer industry, chemical plants, dockyards, oil refinery, and workers exposed to jet fuel in aviation industry.

\section{EXPOSURE ASSESSMENT}

Exposure was evaluated in 7 out of 16 studies. The assessment concerned current and/or cumulative concentration of every single solvent and current and/or cumulative exposure index (the total sum of the ratios between solvent concentration and its threshold limit value, calculated for all solvents in the mixture).

For toluene, the current exposure concentration in the air ranged from 0 to $70 \mathrm{ppm}$, for xylene it ranged from 0-417 ppm; and the current exposure index ranged from 0.5 to 23 [1-3]. The mean lifetime exposure (exposure level $\times$ duration of employment) to toluene ranged from 31-203 ppm, to xylene from 84 to $696 \mathrm{ppm}$, and exposure index from 10 to $67[4,5]$.

The highest-level exposure was encountered in a dockyard [5], and the lowest levels were found in aviation and refinery industries [1,3]. Moderate exposure was observed among painters $[2,4,6]$.

Two studies employed different methods for assessment of solvent exposure. Kaufman et al. calculated the annual estimate as the average sampling for job task $\times$ task frequency (yearly) [7].

Kim et al. used a score system to evaluate exposure; a score from 0-3 was assigned to noise exposure and that of $0,1,2$ to solvent exposure (exposure index was scored respectively as $0.046,0.256$, and 0.875 ). The subjects were classified as exposed to solvents when the cumulative index (exposure level $\times$ years) was higher than 10 (this corresponded to e.g. over 11 years' exposure to low solvent concentrations or over 3 years' exposure to high solvent concentrations) [1].

The method of biological monitoring (metabolites in blood and urine) was applied in one study [6].

\section{HEARING OUTCOME EVALUATION}

Eight studies evaluated the risk/odds ratio of hearing loss due to solvent exposure (Fig. 1 and Fig. 2) [1-5, 7-9, 12]. Age, noise exposure, and employment duration were the variables included most frequently in the multivariate logistic regression models; in some studies, gender, alcohol consumption, hypertension, diabetes, smoking, noise trauma, and family history were also incorporated.

As regards the risk assessment of hearing loss, a few studies evaluated this outcome at high frequency [1-3], some at all frequencies $[4,5,9]$, and two at middle speech frequencies [7,8].

Eleven studies assessed the effect of solvent exposure on audiometric hearing threshold; five papers evaluated central effects on hearing (stapedial decay and contralateral stapedial reflex, interrupted and distorted speech, evoked cortical response, and cognitive response) [3,13-16]. One study concerned otoacoustic emission [6]. Also, in our latest study (unpublished paper), we measured the otoacoustic emission, the auditory brainstem responses, and P-300 wave. In one study, hearing loss was assessed subjectively with a questionnaire [8]. 


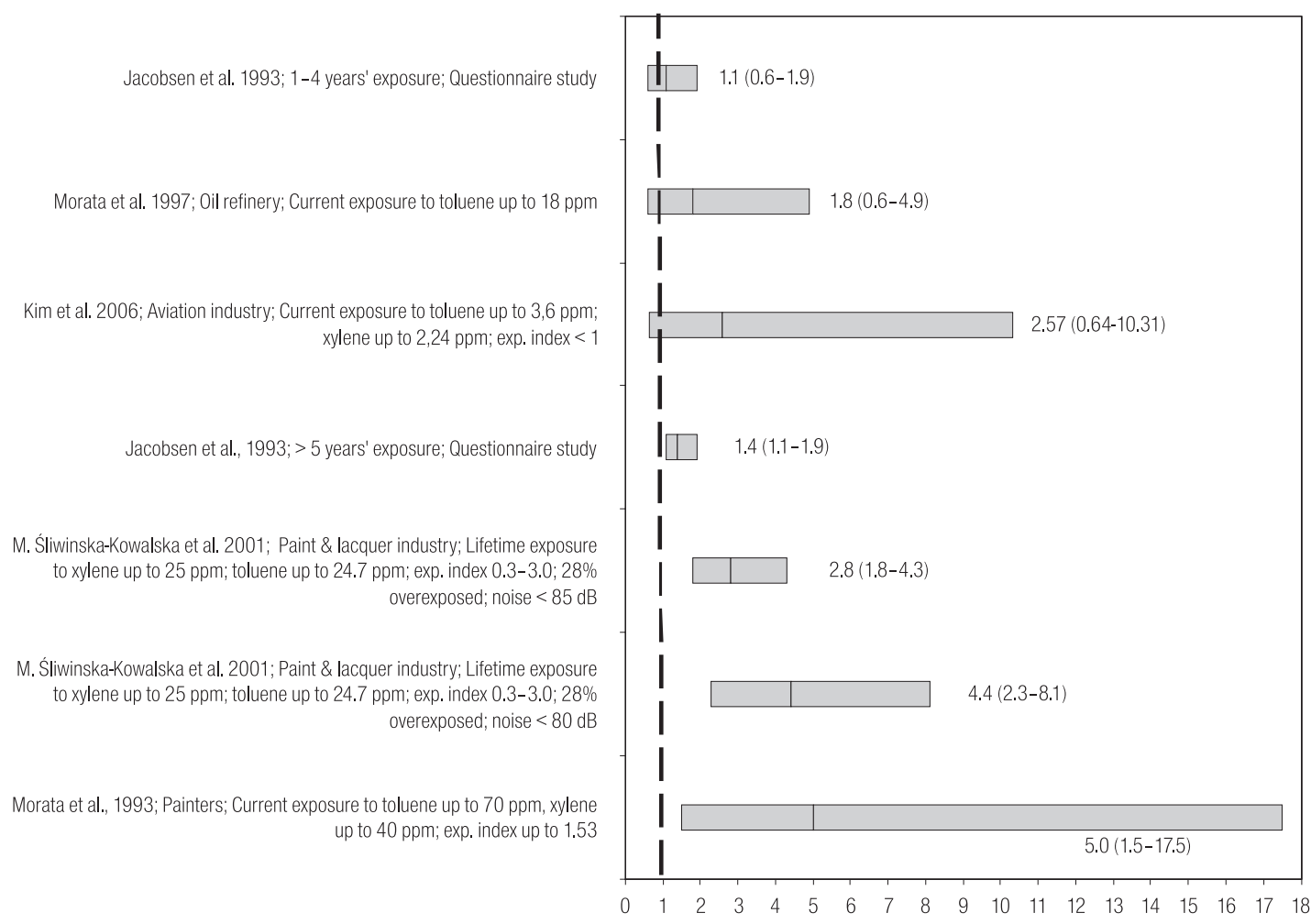

Fig. 1. Risk/odds ratio of hearing loss due to exposure to organic solvent mixture (solvent-only exposed populations).

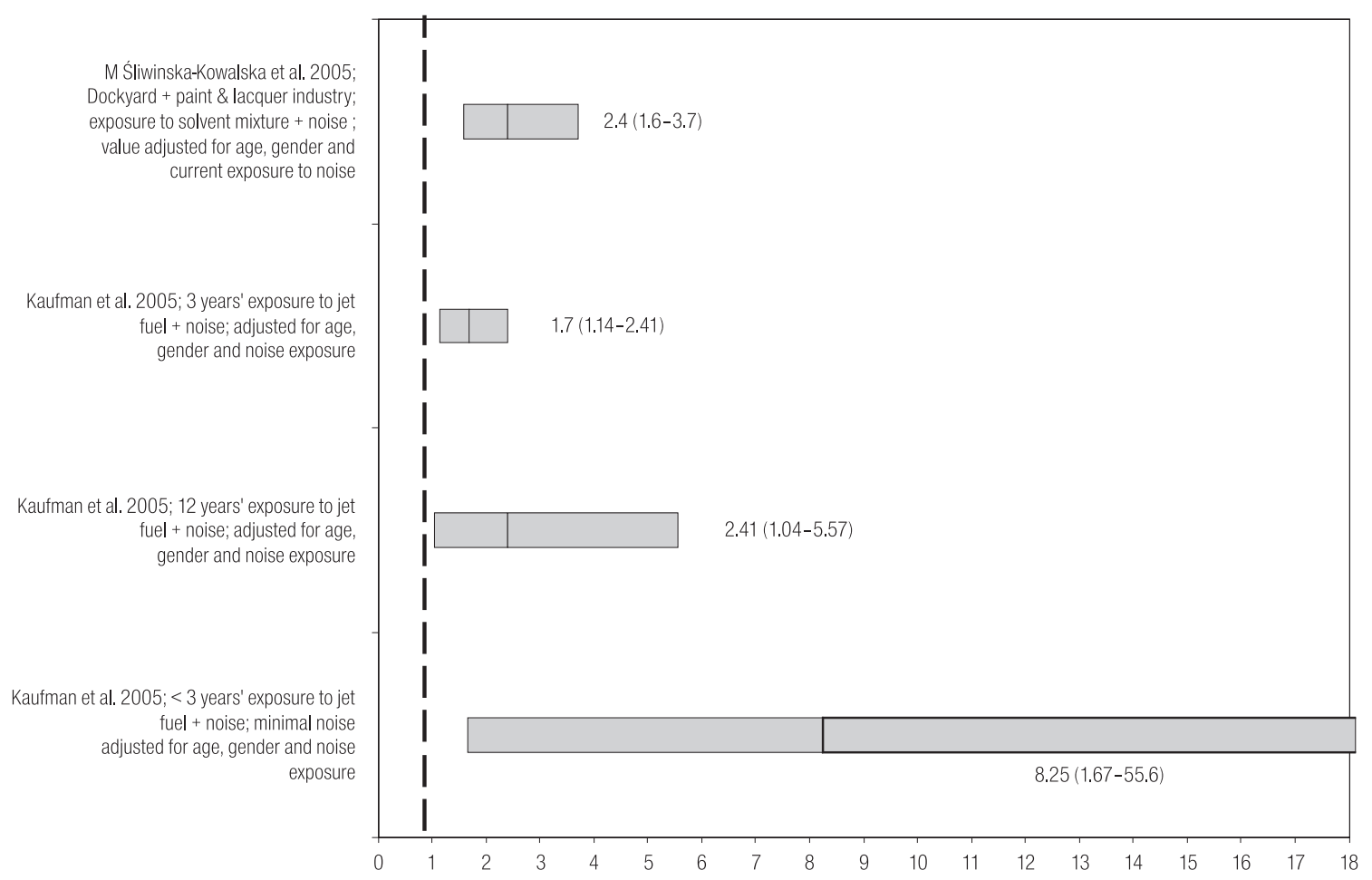

Fig. 2. Risk/odds ratio of hearing loss due to exposure to organic solvent mixture (populations co-exposed to noise and solvents). 


\section{EXPOSURE LEVEL AND HEARING LOSS}

\section{Risk/odds ratio of hearing loss}

No excess risk, compared to non-exposed population, was found for workers exposed to solvent mixture when:

- the exposure history was short (up to 4 years) (Fig. 1) [8],

- the exposure level was very low (e.g. in oil refinery and aviation industry, where the current exposure ranged from few to $18 \mathrm{ppm}$ for toluene, to few ppm for xylene and other solvents, and the exposure index was $<1$ ) (Fig. 1) [1,3].

Excess risk, compared to non-exposed population, was found for workers exposed to solvent mixture when:

- the exposure level was moderate (as it was found for painters in whom toluene exposure ranged from 25-70 ppm, xylene exposure 25-40 ppm, and exposure index from 0.3-1.53) (Fig. 1) [2,4],

- the workers were exposed to high solvent concentrations and noise (as in dockyard workers for whom the mean lifetime exposure to xylene was $696 \mathrm{ppm}$, to toluene $203 \mathrm{ppm}$, and the mean exposure index was 6.3 (Fig. 2) [5,9].

In solvent exposure, the risk of hearing loss was found to increase with the increasing duration of employment (Fig. 2) [7].

\section{Linear relationship}

\section{Risk of hearing loss}

In the study by M. Śliwińska-Kowalska et al., no dose-response relationship was found between moderate solvent exposure (main component xylene) and the risk of hearing loss in 516 paint and lacquer factory workers [4]. Such a correlation was found by M. Śliwińska-Kowalska et al. in 517 dockyard workers exposed to organic solvent mixture (main component xylene) at very high concentrations and co-exposed to noise; ORs for hearing loss were by 1.004 higher for each increment in the index of lifetime exposure to solvents [5].

In the study by L. Kaufman et al., no dose-response relationship was noted for cumulative exposure to jet fuel in 90 aviation industry workers [7]. However, the duration of exposure was significant in the model for persistent hearing loss.

\section{Hearing acuity (threshold)}

In the study by M. Śliwińska-Kowalska et al., multiple linear regression analysis revealed a correlation between exposure to solvent mixture (expressed as a lifetime exposure index) and hearing threshold at $8 \mathrm{kHz}$ in dockyard workers [5]. The same authors have demonstrated a similar relationship for 4, 6 and $8 \mathrm{kHz}$, when the analysis concerned dockyard and paint $\&$ lacquer industry workers (high and moderate solvent exposure, respectively) [9].

\section{CONCLUSIONS}

There is a threshold level for developing hearing loss as a result of occupational exposure to organic solvent mixture; very low exposures (current exposure of up to $25 \mathrm{ppm}$ for toluene and up to $3 \mathrm{ppm}$ for xylene) did not produce any effect on hearing; and very short exposures (1-4 years') were also unlikely to have any impact.

Moderate exposures to organic solvent mixture (below TLV for each solvent, around and above TLV for solvent mixture) have been shown to increase the odds ratio of hearing loss. Thus, current exposure limits for solvents, established separately for each compound, are probably not satisfactory for the hearing protection when mixed solvent exposure is involved.

In the population exposed to high concentrations of organic solvents (current exposure to xylene of up to $417 \mathrm{ppm}$, exposure index up to 31), a linear dose-response relationship was shown between exposure level (expressed as a lifetime exposure index) and the risk of hearing loss, as well as the hearing threshold at high frequencies $(8 \mathrm{kHz}$ in principle).

The interaction between solvents and noise on the risk of hearing loss is unclear, e.g. in combined exposures with lower levels of noise exposure, the effect of solvents was more pronounced [7].

The following factors should be considered when trying to explain why some studies did not show the dose-response relationships: 
1. For the dose:

- the composition of solvent mixture differs and the effects of the possible interactions between these different components on hearing are unknown (theoretically, they could be synergistic, but an antagonistic effect is also plausible):

- the exposures were too low to show the effect,

- only air monitoring was applied, while biological monitoring (metabolites in urine) might be more appropriate (as shown for toluene-only exposed workers).

2. For the response:

- different methods of hearing loss assessment were used,

- pure tone audiometry might not be the most sensitive test to show the solvent effect when studying the dose/response relationship.

In conclusion, there is increasing evidence from epidemiological studies that exposure to organic solvent mixture is associated with an increased risk of hearing loss. However, based on existing data, it is difficult to derive a dose-response relationship between the solvent concentration and the hearing outcome. Although there is no consensus on the lowest occupational exposure limits (OELs) for solvents in relation to their effect on the auditory organ, the current OELs as well as the hearing conservation programs for solvent-exposed populations seem to be inadequate. Since organic solvents have detrimental effects both on the peripheral and central parts of the auditory pathway, pure-tone audiogram might be insufficient to monitor their ototoxicity.

\section{REFERENCES}

1. Kim J, Park H, Ha E, Jung T, Paik N, Yang S. Combined effects of noise and mixed solvents exposure on hearing function among workers in the aviation industry. Ind Health 2005;43:567-73.

2. Morata T, Dunn D, Kretschmer L, Lemasters G, Keith R. Effects ofoccupationalexposureto organic solventsandnoise on hearing. Scan J Work Environ Health 1993;19(4):245-54.

3. Morata TC, Engel T, Durao A, Costa TRS, Krieg EF, Dunn DE, et al. Hearing loss from combined exposures among petroleum refinery workers. Scand Audiol 1997;26:141-9.
4. Śliwińska-Kowalska M, Zamysłowska-Szmytke E, Szymczak W, Kotyło P, Fiszer M, Dudarewicz A, et al. Occupational solvent exposure at moderate concentration increases the risk of hearing loss. Scand J Work Environ Health 2001;27(5):335-42.

5. Śliwińska-Kowalska M, Zamysłowska-Szmytke E, Szymczak W, Kotyło P, Fiszer M, Wesołowski W, et al. Effects of co-exposure to noise and mixture of organic solvents on hearing loss in dockyard workers. J Occup Environ Med 2004;46:30-8.

6. Sułkowski WJ, Kowalska S, Matyja W, Guzek W, Wesołowski W, Szymczak W, et al. Effects of occupational exposure to a mixture of solvents on the inner ear: a field study. Int J Occup Med Environ Health 2002;15(3):247-56.

7. Kaufman LR, LeMasters GK, Olsen DM, Succop P. Effects of concurrent noise and jet fuel exposure on hearing loss. J Occup Environ Med 2005;47:212-8.

8. Jacobsen P, Hein HO, Suadicani P, Parving A, Glytelberg F. Mixed solvent exposure and hearing impairment: an epidemiological study of 3284 men. The Copenhagen male study. Occup Med 1993;43:180-4.

9. Śliwińska-Kowalska M, Zamysłowska-Szmytke E, Szymczak W, Kotyło P, Fiszer M, Wesołowski W, et al. Exacerbation of noise-induced hearing loss by co-exposure to workplace chemicals. Environ Toxicol Pharmacol 2005;19:547-53.

10. Barregård L, Axelsson A. Is there an ototraumatic interaction between noise and solvents? Scand Audiol 1984;13(3):151-5.

11. Bergström B, Nyström B. Development of hearing loss during long-term exposure to occupational noise. A 20-year follow-up study. Scand Audiol 1986;15(4):227-23.

12. El-Shazly A. Toxic solvents in car paints increase the risk of hearing loss associated with occupational exposure to moderate noise intensity. B-ENT 2006;2:1-5.

13. Laukli E, Hansen PW. An audiometric test battery for the evaluation of occupational exposure to industrial solvents. Acta Otolaryngol 1995;115(2):162-4.

14. Möller C, Ödkvist LM, Thell J, Larsby B, Hyden D, Bergholtz LM, et al. Otoneurological findings in psycho-organic syndrome caused by industrial solvent exposure. Acta Otolaryngol (Stockh) 1989;107:5-12 
15. Niklasson M, Arlinger S, Ledin T, Möller C, Ödkvist L, Flodin $\mathrm{U}$, et al. Audiological disturbances caused by long-term exposure to industrial solvents. Relation to the diagnosis of toxic encephalopathy. Scand Audiol 1998;27(3):131-6.
16. Ödkvist LM, Arlinger SD, Edling C, Larsby B, Bergholtz LM. Audiological and vestibulo-oculomotor findings in workers exposed to solvents and jet fuel. Scand Audiol 1987;16(2):75-81. 